\title{
Development of basic psychological need satisfaction in physical education
}

\section{Effects of a two-year PE programme}

\author{
Irina Burchard Erdvik ${ }^{1 \star}$, Tommy Haugen ${ }^{2}$, Andreas Ivarsson ${ }^{3}$ \\ and Reidar Säfvenbom ${ }^{4}$ \\ ${ }^{1}$ Inland Norway University of Applied Science; ${ }^{2}$ University of Agder; ${ }^{3}$ Halmstad University; \\ ${ }^{4}$ Norwegian School of Sports Sciences
}

\begin{abstract}
Research shows that sports-active students experience more basic need satisfaction (autonomy, competence, relatedness) in physical education (PE) than their non-sports-active peers, and thus, reap most of the benefits of PE. This study aimed to investigate the role of a two-year PE programme, referred to as Interest-based PE, in contributing to students' basic need satisfaction in PE, and in particular, to assess potential basic needs-benefits among students who were not involved in leisure-time sport. Among 693 students, 348 were offered a choice of two different PE approaches ("explorative" vs. "sports" approach) for the next two years, while the remaining students continued to receive traditional PE. Girls, non-sports-active students, and students who experienced less need satisfaction in PE at baseline were more likely to choose the explorative approach, thereby signifying a wish for a less sports-centred PE. However, no significant differences in autonomy, competence, and relatedness need satisfaction were identified between Interest-based PE groups and their respective control groups over the course of the programme. Sports active students experienced more gains in relatedness need satisfaction than non-sports active students over the course of the programme, suggesting that challenges in promoting equal opportunities for learning in PE may require more than "Interest-based PE".
\end{abstract}

Keywords: Basic needs; self-determination theory; adolescents; organized sport

Received: September, 2018; Approved: May 2019; Published: November, 2019

Physical education (PE) has long been criticised for its adherence to a sports discourse, characterized by teacher and student emphasis on "sports-techniques" (Tinning, 2010, p. 2) in traditional sports and games (Kirk, 2010, p. 48; Nyberg \& Larsson, 2014). The reproduction of sports in the context of PE is a challenge for students who do not participate in organized sports during their leisure time, as these

^Correspondence: Irina Burchard Erdvik, e-post: irina.erdvik@inn.no

(C) 2019 I. B. Erdvik, T. Haugen, A. Ivarsson and R. Säfvenbom. This is an Open Access article distributed under the terms of the Creative Commons Attribution 4.0 International License (https://creativecommons.org/licenses/by$\mathrm{nc} / 4.0 /$ ), allowing third parties to copy and redistribute the material in any medium or format and to remix, transform, and build upon the material for any purpose, even commercially, provided the original work is properly cited and states its license. 
students experience lower levels of basic need satisfaction (autonomy, competence, and relatedness; Erdvik, Haugen, Ivarsson, \& Säfvenbom, 2019a; Viira \& Koka, 2012), and autonomous motivation (Koka \& Hein, 2003; Säfvenbom, Haugen, \& Bulie, 2015) in PE. Such inequities between sports active and non-sports active students in PE may affect students' learning opportunities in the subject (Cothran, 2010; Hay \& Macdonald, 2010; Nyberg \& Larsson, 2014), and is incompatible with the Norwegian Education Act's official goal of creating a PE learning environment that promotes learning for all (Opplæringslova, 1998, \ 1-3).

In an effort to deal with this challenge and provide equal education for all, PE teachers develop local PE-projects in an attempt to level the playing field for all students. Interest-based PE was such a project, developed to improve students' PE experiences of autonomy and thus competence and relatedness, by offering them a choice between two activity approaches to PE: a sports approach (SA), centred on traditional organised sports; and an explorative approach (EA), offering a less sports-centred, more playful approach to PE. This study investigates the role of Interest-based PE in promoting students' autonomy, competence, and relatedness need satisfaction in $\mathrm{PE}$, with particular emphasis on non-sports active adolescents.

\section{Theoretical framework}

Self-determination theory (SDT) and its sub-theory of basic psychological needs describe interpersonal and contextual influences on adolescents' motivational learning behaviour (Ryan \& Deci, 2017, p. 6). The SDT framework (Ryan \& Deci, 2017, p. 222) postulates the existence of autonomy, competence, and relatedness as three basic psychological needs. The need for autonomy has been described as the need to experience volition and psychological freedom, denoting self-endorsed behaviour stemming from the true self (Ryan \& La Guardia, 2000). The need for competence is commonly referred to as the need to experience mastery through interaction with the social environment (Deci \& Ryan, 2000). Relatedness concerns the need to feel connected to others, to be cared for and experience a sense of belonging with significant others (Deci \& Ryan, 2000; Ryan \& La Guardia, 2000). From the perspective of SDT, these three psychological needs are considered fundamental to autonomous motivation and constitute universal, organismic, interdependent necessities for motivated behaviour, learning, thriving, and psychological growth across all contexts and all stages of human development (Ryan \& Deci, 2017, p. 242; Ryan \& La Guardia, 2000).

Basic need satisfaction is important for students' holistic development in schools and may have implications for learning and educational outcomes (Ryan \& Deci, 2017, p. 352). As school is a key developmental context in the lives of children and adolescents, Ryan and Deci (2017, p. 353) argue that it should emphasise the importance of basic need satisfaction in students' development as thriving learners. Research on basic need satisfaction and autonomous motivation in PE has identified these constructs as positively related to various facets of positive development, such as general well-being 


\section{B. Erdvik et al.}

(Bagøien, Halvari, \& Nesheim, 2010), feelings of self-worth (Erdvik, Haugen, Ivarsson, \& Säfvenbom, 2019a; Garn, McCaughtry, Martin, Shen, \& Fahlman, 2012), increased quality of effort (Ntoumanis, 2001; Standage, Duda, \& Ntoumanis, 2006; Taylor \& Lonsdale, 2010), concentration (Erturan-İlker, Quested, Appleton, \& Duda, 2018; Ntoumanis, 2001, 2005), persistence (Standage et al., 2006), preference for challenging tasks (Standage, Duda, \& Ntoumanis, 2005), experience of positive affect (Standage et al., 2005), feelings of flow (Stormoen, Urke, Tjomsland, Wold, \& Diseth, 2016), and intentions to take part in optional PE (Ntoumanis, 2005) as well as leisure-time physical activity (Chen, 2014; Erdvik, Øverby, \& Haugen, 2014; Ntoumanis, 2001; Standage, Duda, \& Ntoumanis, 2003). Further, basic need satisfaction and autonomous motivation in PE have been identified as inversely related to boredom (Ntoumanis, 2001) and negative affect (Ntoumanis, 2005; Standage et al., 2005). As such, while research suggests that emphasis on basic need satisfaction in PE may be important to secure positive and healthy development among children and adolescents (Ryan \& Deci, 2017, p. 242), basic need satisfaction may also encourage participation in PE and make children and adolescents more receptive to learning as they take part in the subject.

\section{Interest-based PE}

Experiencing that students did not benefit equally in PE, PE-teachers and local college PE-teacher education lecturers developed the Interest-based PE project. Like other local, experience-based, didactical projects developed in the everyday-life of teachers, Interest-based PE had limited access to scientific expertise and financial funding, and was thus not developed as a classical intervention study, nor as an action research project. Interest-based PE was teachers' attempt to make PE a developmental asset for all, and the program aimed to promote basic need satisfaction by offering students a choice of two different PE approaches: an explorative approach (EA) and a sports approach (SA). Both approaches were based on the Norwegian PE curriculum and the therein described competence aims (Utdanningsdirektoratet, 2015). EA and SA were designed to offer students different approaches to learning in PE. Other aspects of PE, such as assessment procedures (e.g., Krijgsman et al., 2017) and the communication of purposes and learning objectives (e.g., Nyberg \& Larsson, 2014), were not explicitly targeted by the Interest-based PE programme. Within this programme, students who chose SA were offered traditional sporting activities and ballgames in their PE class, which allowed them to play the sports according to the traditional rules, techniques, and logics of sports. The students who chose EA were, on the other hand, offered a less sports-centred and more playful approach to movement activity in their PE. More specifically, PE educators who taught EA would provide games (e.g., "tag", "red light green light", "hunter hawks") or modified sports (e.g., use mulitple balls, play while attached to a fellow student) to encourage meaningful participation for a group of students that is not necessarily inspired by the logic of sports (for more information, see Tangen, \& Huseby, 2018). 
Consequently, teachers established two different PE classes based on students' choices. Self-selection into EA or SA was intended to promote the students' autonomy as students were allowed to choose the PE programme they experienced to be more relevant to their personal interests (Katz \& Assor, 2007). However, Interestbased PE was also expected to increase students' competence and relatedness because self-selection into EA and SA meant that PE was taught in more homogenous groups and because students could choose a PE that aligned with their personal and cultural values (Katz \& Assor, 2007).

\section{Research questions}

As mentioned above, basic need satisfaction is important for students' learning in school. Although the provision of student choice is associated with motivational outcomes (e.g., How, Whipp, Dimmock, \& Jackson, 2013; Patall, 2012), it remains unclear whether a single choice between two activity approaches to PE is sufficient to promote students' autonomy, competence, and relatedness in the subject (Patall, 2012). Nevertheless, knowing that adolescents may not experience equal basic-need benefits in traditional PE (Erdvik, Haugen, Ivarsson, \& Säfvenbom, 2019a), Interest-based PE was expected to be particularly beneficial for students who were not involved in leisure-time sport. As such, the aim of this study was to determine the role of Interest-based PE in students' development of basic need satisfaction in PE, with particular emphasis on non-sports active adolescents. More specifically, this study raised two research questions:

(I) Does the two-year Interest-based PE programme affect students' satisfaction of the three basic psychological needs for autonomy, competence, and relatedness in PE?

(II) Are student trajectories of autonomy, competence, and relatedness need satisfaction, through the two-year Interest-based PE programme, contingent on participation in leisure-time sport?

\section{Method}

\section{Participants}

A controlled study of Interest-based PE was possible as participants were part of a larger research project, referred to as 'the Relevance of Physical Activity Contexts in the Everyday Life of Adolescents' (REPAC). Including the Interest-based PE participants, REPAC comprised 4180 lower and upper secondary school students from four Norwegian counties. The REPAC-study was longitudinal and the data collected from 2014 to 2016 were derived from annual questionnaire responses given by two cohorts (born 1997/2000) of adolescents during their three years in lower and upper secondary school. In one of the REPAC-counties, PE teachers at nine participating schools introduced Interest-based PE to altogether 348 students. Entering their second year of lower or upper secondary school, these students received 


\section{B. Erdvik et al.}

Interest-based PE for the two next years. Because the students could choose between two PE approaches, two subgroups were established: those who chose EA and those who chose SA. Matched control groups were created for EA and SA based on responses from participants in the overall REPAC study who did not participate in Interest-based PE. These were comparable with respect to age (e.g., Ntoumanis, Barkoukis, \& Thøgersen-Ntoumani, 2009), sex (e.g., Viira \& Koka, 2010), leisure-time sport involvement (e.g., Erdvik, Haugen, Ivarsson, \& Säfvenbom, 2019a), and basic need satisfaction reported at baseline. The present study is based on data collected from 693 students (348 Interest-based PE participants, and 345 assigned controls).

\section{Data collection}

Data was collected by means of an online survey, delivered during traditional school hours in the presence of a teacher and a project researcher, both of whom were available to answer students' questions. Data collections lasted 60-80 minutes and took place between March and May for three consecutive years (see figure 1). Participation was voluntary. Participants younger than 15 years of age were included based on parental consent, while older students were included based on independent consent. The study was approved by the Norwegian Centre for Research Data and by the school principals.

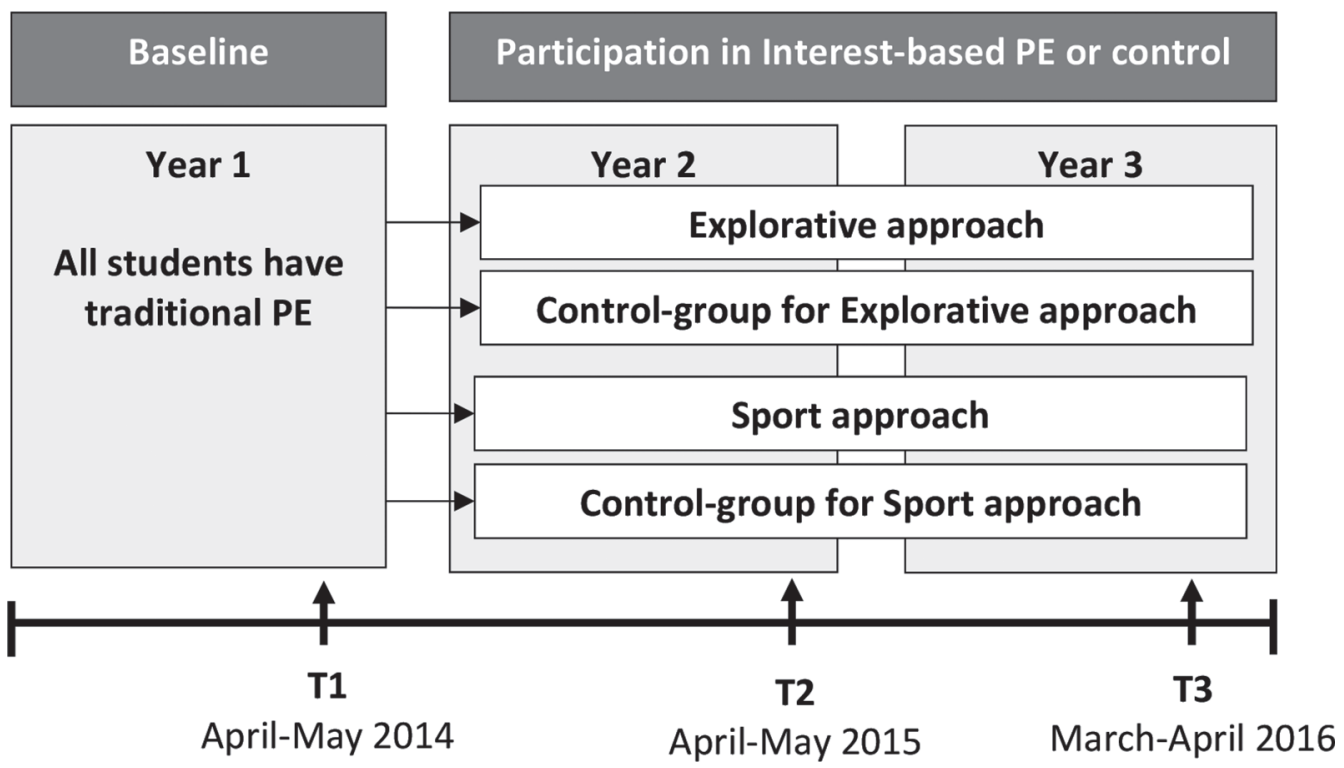

Figure 1. Interest-based PE timeline.

Note. At T1, all students were about to finish their first year of lower/upper secondary school. Interest-based PE was initiated in the beginning of the second school year of lower/upper secondary school, and allowed participants to choose between a "sport approach" an "explorative approach" to PE. The two control groups continued to receive traditional PE. Interest-based PE participants had participated in the sport approach or the explorative approach for nearly one year at T2, and for nearly two years at T3. 


\section{Instruments}

Satisfaction of Basic Psychological Needs (BPN) in PE was measured using the 12-item Basic Psychological Needs in Exercise Scale (BPNES; Vlachopoulos \& Michailidou, 2006), which for the purpose of this study was adapted for use in a PE context. Participants reported their satisfaction of the need for autonomy (e.g., "Physical education classes are in agreement with my choices and interests"), competence (e.g., "I feel that I have made a lot of progress in relation to the objective of physical education") and relatedness (e.g. "I feel very comfortable with the students in PE") across three time points on a Likert scale ranging from 1 (totally disagree) to 7 (very strongly agree). The BPNES is reported to be valid and reliable, with alpha coefficient of $.75, .80$, and .86 for autonomy, competence, and relatedness need satisfaction, respectively.

Additionally, adolescents reported their sex and year of birth. The latter was used to distinguish between adolescents in two cohorts, attending either lower or upper secondary school (13, 14 and 15, versus 16, 17 and 18 years of age). Participants also reported whether or not they were involved in organized sports outside of school at baseline (i.e., "Do you train or compete in a sports club?").

\section{Statistical analyses}

Descriptive statistics were computed using IBM SPSS 25, while second order growth curve analyses of students' growth trajectories of autonomy, competence, and relatedness need satisfaction were, in line with the recommendations of Newsom (2015), performed using the MLR estimator in Mplus version 8.0. Bivariate correlations, means, standard deviations, skewness, and kurtosis were estimated for autonomy, competence, and relatedness at each time point, based on 2000 bootstrap samples. The magnitude of the correlations were interpreted according to Cohen's definitions (small $\geq .10$, medium $\geq .30$, and large $\geq .50$; Cohen, 1988, pp. 79-80). Bootstrapped independent samples t-tests, which are considered robust to various distributional assumptions (Wright, London, \& Field, 2011), were used for drop-out analyses and comparisons of autonomy, competence, and relatedness need satisfaction at each measurement point. The Pearson chi square test and the independent samples t-test were used for descriptive analyses of students' choice between the two PE approaches, and effect sizes were calculated and interpreted according to Cohen's definitions (Cohen's d, small $\geq .20$, medium $\geq .50$, large $\geq .80$; Cohen, 1988, pp. 24-26). Second order growth curve analyses were performed to study the Interest-based PE programme's possible effect on growth trajectories of autonomy, competence, and relatedness need satisfaction in PE. To specify the second order growth curve model we used the syntax suggested by Newsom (2015). In the model specification strict invariance were specified. The same analytical approach was used to study possible effects of leisure-time sport participation at baseline on growth trajectories of basic 


\section{B. Erdvik et al.}

need satisfaction among students participating in EA or SA. Effects of students' participation in Interest-based PE groups versus control groups were studied by means of regressing dichotomous group variables (EA vs. EA-control, and SA vs. SA-control) on the growth trajectories of autonomy, competence, and relatedness need satisfaction in PE. The same approach was used to study possible effects of students' leisure time sport participation at T1 (sports vs. no sports) on growth trajectories of autonomy, competence, and relatedness need satisfaction among students in the two Interest-based PE groups (EA and SA). Model fit was evaluated by means of the Root Mean Square Error of Approximation (RMSEA), the Comparative-fit index (CFI), the Tucker-Lewis index (TLI), and the Standardized Root Mean Square Residual (SRMR). CFI and TLI values around .90 in combination with SRMR and RMSEA values around .08 indicated acceptable model fit (Marsh, 2007 , p. 786). In all analyses, $p$-values below .05 were considered to indicate statistically significant results.

\section{Results}

As shown in table 1, all variables included in the present study showed acceptable levels of internal consistency and medium to large correlation effects.

Table 1. Descriptive statistics for study variables (based on all study participants)

\begin{tabular}{llcccccccc}
\hline Correlations & 1 & 2 & 3 & 4 & 5 & 6 & 7 & 8 & 9 \\
\hline $1 \quad$ Autonomy t1 & - & $.52^{\star}$ & $.44^{\star}$ & $.88^{\star}$ & $.54^{\star}$ & $.46^{\star}$ & $.67^{\star}$ & $.42^{\star}$ & $.33^{\star}$ \\
$2 \quad$ Autonomy t2 & & - & $.58^{\star}$ & $.53^{\star}$ & $.91^{\star}$ & $.54^{\star}$ & $.42^{\star}$ & $.77^{\star}$ & $.41^{\star}$ \\
$3 \quad$ Autonomy t3 & & & - & $.46^{\star}$ & $.56^{\star}$ & $.91^{\star}$ & $.40^{\star}$ & $.45^{\star}$ & $.75^{\star}$ \\
$4 \quad$ Competence t1 & & & & - & $.56^{\star}$ & $.51^{\star}$ & $.69^{\star}$ & $.45^{\star}$ & $.34^{\star}$ \\
$5 \quad$ Competence t2 & & & & & - & $.58^{\star}$ & $.44^{\star}$ & $.75^{\star}$ & $.41^{\star}$ \\
$6 \quad$ Competence t3 & & & & & & - & $.43^{\star}$ & $.46^{\star}$ & $.79^{\star}$ \\
$7 \quad$ Relatedness t1 & & & & & & & - & $.51^{\star}$ & $.44^{\star}$ \\
$8 \quad$ Relatedness t2 & & & & & & & & - & $.53^{\star}$ \\
$9 \quad$ Relatedness t3 & & & & & & & & & - \\
M & 4.59 & 4.65 & 4.65 & 4.67 & 4.70 & 4.70 & 5.18 & 5.11 & 5.13 \\
SD & 1.36 & 1.41 & 1.42 & 1.29 & 1.37 & 1.35 & 1.26 & 1.37 & 1.36 \\
Range & $1-7$ & $1-7$ & $1-7$ & $1-7$ & $1-7$ & $1-7$ & $1-7$ & $1-7$ & $1-7$ \\
Skewness & -.34 & -.49 & -.37 & -.43 & -.52 & -.51 & -.70 & -.68 & -.64 \\
Kurtosis & -.38 & -.08 & -.14 & -.04 & -.12 & .23 & .33 & .11 & .15 \\
Cronbach's alpha & .88 & .90 & .90 & .86 & .88 & .90 & .85 & .90 & .90 \\
\hline
\end{tabular}


Table 1. (Continued)

\begin{tabular}{lccccccccc}
\hline Correlations & 1 & 2 & 3 & 4 & 5 & 6 & 7 & 8 & 9 \\
\hline $\begin{array}{l}\text { Internvention } \\
\text { groups }\end{array}$ & & & & & & & & & \\
$\quad$ M & 4.61 & 4.69 & 4.59 & 4.67 & 4.73 & 4.65 & 5.16 & 5.06 & 5.04 \\
$\quad$ SD & 1.36 & 1.33 & 1.43 & 1.27 & 1.27 & 1.37 & 1.28 & 1.31 & 1.42 \\
Control groups & & & & & & & & & \\
$\quad$ M & 4.57 & 4.59 & 4.74 & 4.67 & 4.65 & 4.77 & 5.20 & 5.18 & 5.28 \\
$\quad$ SD & 1.40 & 1.50 & 1.33 & 1.30 & 1.48 & 1.31 & 1.25 & 1.45 & 1.26 \\
\hline
\end{tabular}

Note. Descriptive statistics that are based on the entire sample (intervention and control groups combined) include bivariate correlations, ${ }^{\star} p<.01$ (two tailed), means (M), standard deviations (SD), skewness, kurtosis, and Cronbach's alpha. M (SD) are also reported separately for intervention participants (EA and SA combined) and control group participants (EA-control and SA-control combined). With the exception of Cronbach's alpha, all descriptives are based on 2000 bootstrap samples.

Drop-out analyses were performed by means of bootstrapped independent samples t-tests which showed that students who participated at all three time points reported significantly higher levels of autonomy $(M=4.75, \mathrm{SD}=1.29)$, competence $(M=4.78, S D=1.25)$, and relatedness $(M=5.28, S D=1.18)$ need satisfaction at $\mathrm{T} 1$ (baseline) compared to those students who only participated at T1, at T1 and T2, or at T1 and T3 (Autonomy: $\mathrm{M}=4.47, \mathrm{SD}=1.40, t(601.29)=-2.80, p=.005, d=$ -.21 ; Competence: $\mathrm{M}=4.56, \mathrm{SD}=1.32, t(840)=-2.42, p=.016, d=-.18$; Relatedness: $\mathrm{M}=5.02, \mathrm{SD}=1.31, t(588.453)=-2.914, p=.005, d=-.22)$.

Demographic characteristics in table 2 show that the Interest-based PE groups (EA and SA) and their respective controls showed similar characteristics in terms of autonomy, competence, and relatedness need satisfaction, sex, age (lower secondary school cohort vs. upper secondary school cohort), and leisure-time sport participation at baseline. Analyses of students' choice of PE approach show that 52\% (180 students) chose EA whereas 48\% (168 students) chose SA. Students who chose EA reported significantly less autonomy $(t(523)=-8.822, p<.001, d=-.83)$, competence $(t(519)=-9.654, p<.001, d=.94)$, and relatedness $(t(507)=-8.471, p<$ $.001, d=-.90)$ need satisfaction at baseline compared to students who chose SA. Further, there were significant associations between choice of PE approach and student sex as well as between choice of PE approach and leisure-time sport participation (sex: $\chi^{2}(1)=36.975, p=.000$; sport: $\chi^{2}(1)=42.954, p=.000$ ). Based on the odds ratio, the likelihood of girls choosing EA was 3.90 times higher than for boys, and the likelihood of non-sports-active students choosing EA was 4.43 times higher than it was for sports-active students.

Second-order growth curve analyses of students' growth trajectories were applied to test possible effects of the two-year PE programme on students' autonomy, competence, and relatedness need satisfaction in PE. As shown in table 3, all models 


\section{B. Erdvik et al.}

Table 2. Demographic characteristics of Interest-based PE groups and control groups

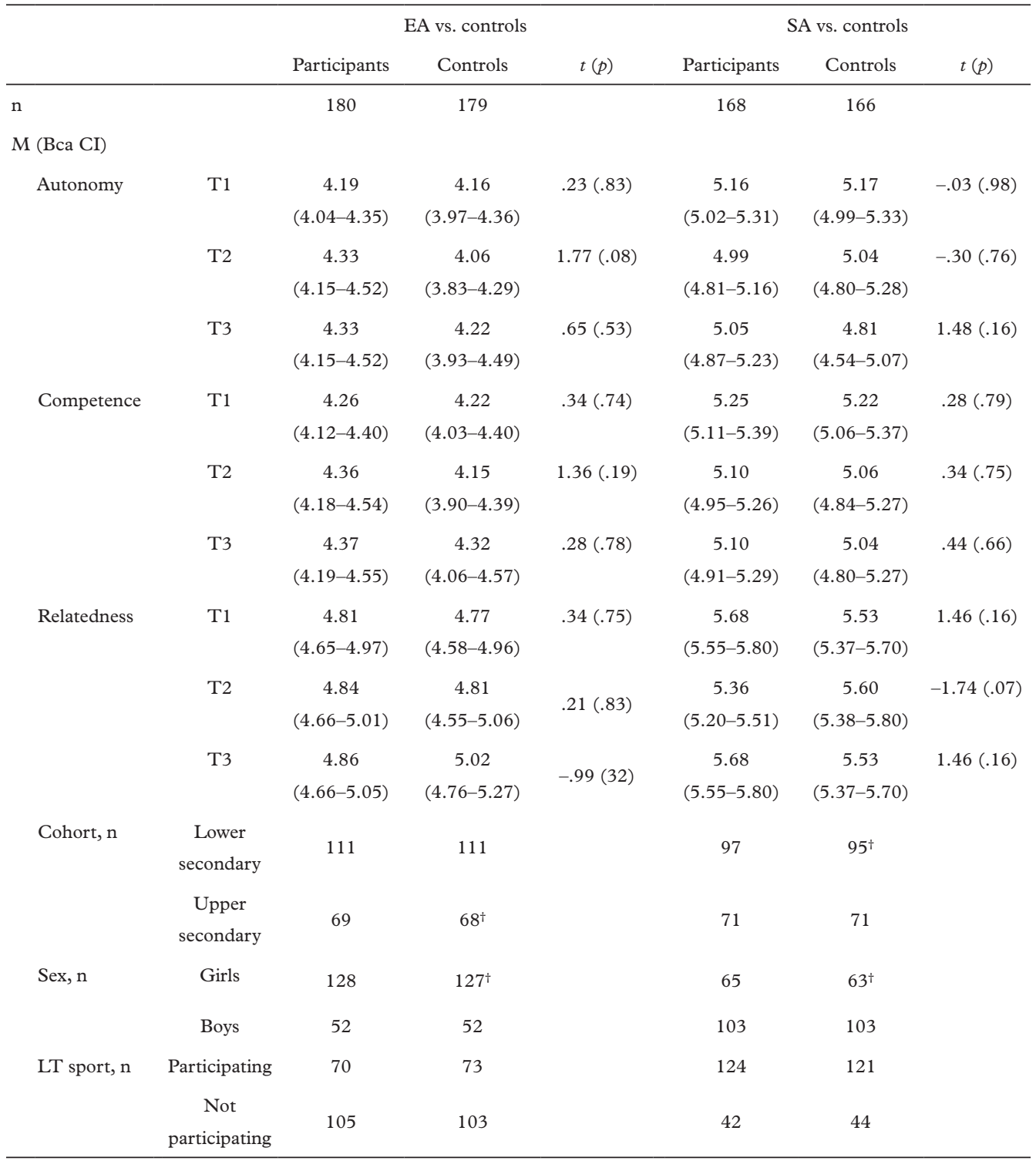

Note. Mean group differences tested with independent samples t-tests (2000 bootstraps). EA = Explorative approach; SA = Sport approach; Autonomy, competence, and relatedness at T1, T2, and T3 are indicated by group means and 95\% bootstrapped CI; LT sport = Leisure-time sport participation at baseline. ${ }^{\dagger}$ Two girls in lower secondary school who attended SM did not participate at T1, while one upper secondary school girl attending EM did not report BPN or sport involvement at T1. Thus, these students were not assigned controls.

showed acceptable fit to the data. Analyses showed that students' participation in Interest-based PE groups versus control groups did not significantly predict students' trajectories of autonomy (EA vs. EA-control: $\beta=-.118, \mathrm{SE}=.068, p=.08$; SA vs. 
SA-control: $\beta=-.107, \mathrm{SE}=.066, p=.10$ ), competence (EA vs. EA-control: $\beta=$ $-.116, \mathrm{SE}=.095, p=.22$; SA vs. SA-control: $\beta=.025, \mathrm{SE}=.064, p=.70$ ), or relatedness (EA vs. EA-control: $\beta=.024, \mathrm{SE}=.085, p=.78$; SA vs. SA-control: $\beta=$ $.092, \mathrm{SE}=.062, p=.14$ ) and need satisfaction in PE (see figure 2).

The second research question - whether student trajectories of autonomy, competence, and relatedness need satisfaction through Interest-based PE were contingent on participation in leisure-time sport - was investigated using similar second-order growth curve analyses (for model fit indices, see table 3). Analyses showed that leisure-time sport participation did not significantly relate to students' trajectories of basic need satisfaction among the SA students (sports vs. no sports: autonomy, $\beta=-.039, \mathrm{SE}=.079, p=.62$; competence, $\beta=-.134, \mathrm{SE}=.077, p=.08$; relatedness, $\beta=-.101, \mathrm{SE}=.072, p=.16$; see figure 3 ). With respect to the EA-students, analyses showed no significant relationship between leisure-time sport participation and trajectories of autonomy and competence need satisfaction in PE (sports vs. no sports: autonomy, $\beta=-.120, \mathrm{SE}=.086, p=.17$; competence, $\beta=-.251, \mathrm{SE}=$ $.139, p=.07)$. However, significant, yet week relations between sports participation and EA-students' trajectories of relatedness in PE were identified $(\beta=-.404, \mathrm{SE}=$ $.192, p=.04)$.

Table 3. Model fit indices

\begin{tabular}{lccccccc}
\hline & $\chi^{2}$ & $d f$ & $p$ & RMSEA (90\% CI) & CFI & TLI & SRMR \\
\hline Autonomy & & & & & & & \\
$\quad$ EA vs. EA-c & 100.060 & 63 & 0.0021 & $.035(.021-.048)$ & .988 & .986 & .041 \\
$\quad$ SA vs. SA-c & 131.658 & 63 & $<.0000$ & $.051(.039-.063)$ & .971 & .964 & .052 \\
EA: Sports vs. no sports & 112.578 & 63 & .0001 & $.052(.036-.068)$ & .976 & .971 & .067 \\
$\quad$ SA: Sports vs. no sports & 138.372 & 63 & $<.0000$ & $.069(.053-.085)$ & .952 & .940 & .094 \\
Competence & & & & & & & \\
EA vs. EA-c & 145.494 & 63 & $<.0000$ & $.053(.041-.064)$ & .974 & .968 & .038 \\
SA vs. SA-c & 196.930 & 64 & $<.0000$ & $.070(.059-.081)$ & .933 & .918 & .063 \\
EA: Sports vs. no sports & 137.428 & 63 & $<.0000$ & $.064(.049-.079)$ & .964 & .955 & .062 \\
SA: Sports vs. no sports & 176.090 & 64 & $<.0000$ & $.084(.069-.098)$ & .921 & .903 & .081 \\
Relatedness & & & & & & & \\
EA vs. EA-c & 145.960 & 63 & $<.0000$ & $.053(.042-.064)$ & .972 & .966 & .046 \\
SA vs. SA-c & 148.115 & 64 & $<.0000$ & $.056(.044-.068)$ & .966 & .959 & .051 \\
EA: Sports vs. no sports & 112.714 & 63 & .0001 & $.052(.036-.068)$ & .974 & .968 & .057 \\
SA: Sports vs. no sports & 103.662 & 64 & .0013 & $.050(.031-.067)$ & .977 & .972 & .055 \\
\hline
\end{tabular}

Note . EA = Explorative approach EA-c $=$ Control group for explorative approach; SA = Sport approach; SA-c = Control group for sport approach. 


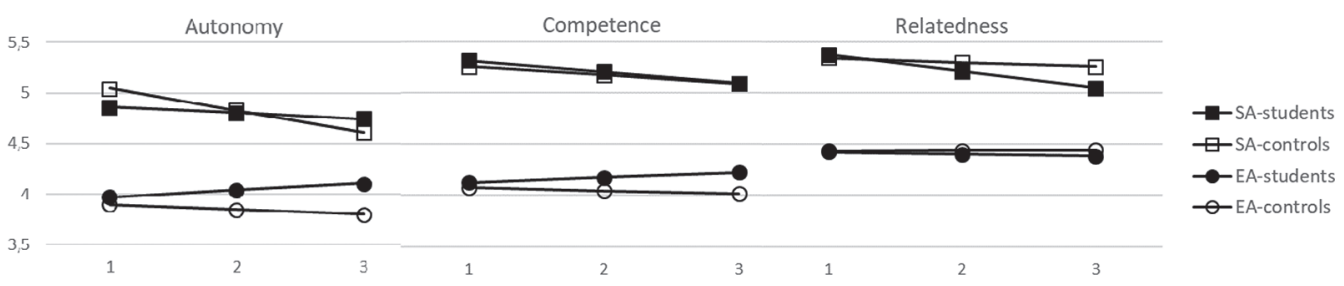

Figure 2. Growth trajectories of autonomy, competence, and relatedness need satisfaction among students in Interest-based PE (EA and SA) and their respective controls.

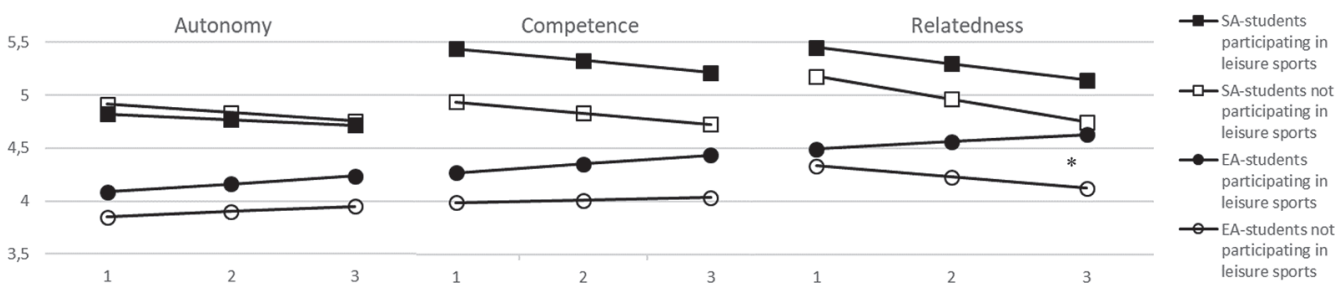

Figure 3. Growth trajectories of autonomy, competence, and relatedness need satisfaction among students who did and did not participate in leisure-time sport within EA and SA, ${ }^{\star} \mathrm{p}<.05$.

\section{Discussion}

The main aim of this study was to investigate the role of a two-year Interest-based $\mathrm{PE}$ programme in levelling the playing field for sports-active and non-sports-active students in terms of their experience of basic need satisfaction in PE.

Second-order growth curve analyses comparing growth trajectories of autonomy, competence, and relatedness need satisfaction of each Interest-based PE group to its corresponding control group showed that neither participation in EA nor in SA significantly influenced students' autonomy, competence, and relatedness need satisfaction in PE. From the perspective of null hypothesis significance testing, this suggests that the PE programme may not have been effective in increasing students' sense of autonomy, competence, and relatedness in the subject. Yet, somehow contradictory to the lack of change, analyses revealed that when given the opportunity, girls, non-sports-active adolescents, and students who experienced less basic need satisfaction in PE at baseline were more likely to choose EA, thereby signifying a wish for a less sports-centred PE subject. This aligns with prior research showing that girls and non-sports-active students typically experience less basic need satisfaction in PE (Erdvik, Haugen, Ivarsson, \& Säfvenbom, 2019a; Viira \& Koka, 2012) and hold less positive views about traditional PE compared to boys and sports-active adolescents (e.g., Kjønniksen, Anderssen, \& Wold, 2009; Säfvenbom, Haugen, \& Bulie, 2015).

An assumption inherent in Interest-based PE was that the introduction of EA would benefit students who were less likely to experience high levels of need satisfaction in 
traditional PE classes, which are typically centred on sport (e.g., Kirk, 2010, p. 48). As such, it was considered possible that Interest-based PE could have a different impact on students' basic need satisfaction depending on whether or not they were involved in leisure-time sport at baseline. With respect to the students who chose SA, no significant differences in autonomy, competence, and relatedness need satisfaction between sports active and non-sports active students were identified. Among the EA-students, there was no significant difference between sports active and nonsports active students' trajectories of autonomy and competence need satisfaction. However, analyses showed that the sports active EA-students developed significantly higher levels of relatedness need satisfaction over the course of the Interest-based PE programme than the non-sports active EA-students. As such, this study suggests that levelling the playing field for sports active and non-sports active students in $\mathrm{PE}$ may require more than what was offered through "Interest-based PE". While there could be several explanations for these results, they align with findings from a qualitative study, developed by Erdvik, Mordal-Moen og Säfvenbom (2019b) to gain a deeper understanding of how the Interest-based PE programme intervened in the relations between the students and the PE subject. Qualitative one-on-one interviews with participating students showed that central aspects of PE remained unchanged through the Interest-based PE programme, and that this approach to PE may therefore not have altered neither teachers' nor students' habitual understanding of PE. The next section discusses assessment practices and discourses, as central aspects of PE that were not targeted by the Interest-based PE programme and that therefore could contribute explain Interest-based PE's inability to promote students' autonomy, competence, and relatedness need satisfaction in PE.

\section{Sports discourse and assessment in PE}

A central aspect of PE that did not change with the Interest-based PE programme is that PE was delivered and assessed according to the Norwegian PE curriculum and the therein described competence aims (Utdanningsdirektoratet, 2015). However, assessment is described as a troublesome issue in PE (Leirhaug \& Annerstedt, 2016; López-Pastor, Kirk, Lorente-Catalán, MacPhail, \& Macdonald, 2013; Redelius \& Hay, 2012; Svennberg, Meckbach, \& Redelius, 2018) and a challenge to students' experiences of autonomy, competence, and relatedness in the subject (Krijgsman et al., 2017; Slingerland et al., 2016). Previous research found that students consider "having the right body and sporting ability" (Redelius \& Hay, 2012, p. 218) to be a key factor in receiving high grades in PE. If students experience their PE assessment as a judgement of sports performance, and not as assessment for learning in relation to curricular competence aims (e.g., Leirhaug \& Annerstedt, 2016), this may have negative consequences for their sense of basic need satisfaction (e.g., Krijgsman et al., 2017) and thus, learning in the subject (Cothran, 2010; Hay \& Macdonald, 2010; Ryan \& Deci, 2017, p. 175). It is therefore important to note that Interest-based 


\section{B. Erdvik et al.}

PE did not explicitly target teachers' communication of purposes and competence aims in PE and thus, there is little to suggest that Interest-based PE helped students recognize the educational aspects of $\mathrm{PE}$, nor that it prevented students from experiencing a "hidden curriculum" of sports (Nyberg \& Larsson, 2014, p. 12). Arguably, Interest-based PE may not have offered participating teachers sufficient support to achieve constructive alignment of curriculum, teaching, learning, and assessment in PE. The programme may therefore have done little to challenge existing ideas about what it means to be good at PE. This interpretation is supported by findings from qualitative interviews with students who participated in the Interest-based PE programme (Erdvik, Mordal-Moen, \& Säfvenbom, 2019b). All in all, findings from this study and from the study of Erdvik, Mordal-Moen og Säfvenbom (2019b) do much to suggest that the sports discourse prevailed regardless of Interest-based PE and the activities that students were presented with.

According to Kirk, "physical-education-as-sports-techniques" represents "a highly institutionalised and deeply sedimented practice" (Kirk, 2010, p. 50), and several researchers have shown that teachers struggle to distance themselves from the practice of PE-as-sports (e.g., Green, 2000; Mordal-Moen \& Green, 2014). As such, while the activity opportunities may have been changed through Interest-based PE, teachers' and students' understandings of PE-as-sports may have acted as a barrier to students' need satisfaction. This may also explain why basic need satisfaction remains stable over the course of this study, despite the changes that were made through the delivery of EA and SA. From a SDT perspective, peoples' sense of basic need satisfaction is considered to be changeable and to vary across time, contexts and social interactions (Ryan \& Deci, 2017, p. 243). However, one cannot rule out the possibility that students and their teachers over years have internalized a sports discourse in PE. An underlying understanding of 'PE-as-sports' may not only have made it hard for the PE teachers to change their approach to teaching PE - as suggested by Erdvik, Mordal-Moen, \& Säfvenbom (2019b), these understandings may also be reflected in the ways their students have learned to value their own accomplishments in the subject. As such, within both approaches to PE, teachers may have continued to teach PE-as-sports and students may have continued to judge their own PE accomplishments according to the logic of sports - thus challenging the promotion of students' autonomy, competence, and relatedness, regardless of Interest-based PE. All in all, prior research gives reason to believe that a lack of curriculum clarification reduced Interest-based PE to no more than a small interference in teachers' and students' histories of $\mathrm{PE}$, and thus, that the sport discourse and assessment procedures remained at the centre of the subject. Together with findings from Erdvik, Mordal-Moen og Säfvenbom (2019b) qualitative study on Interest-based PE, analyses from the present study suggest that attempts to reduce or even erase the "social inequity and injustice and reproduced privilege" (Stolz, 2014, p. 27) associated with PE-as-sports require more comprehensive long term strategies, directed towards PE teachers' habitus, interpretations of the curriculum, and discourses that compete for influence 
in PE (Kirk, 2010, p. 139; Stolz, 2014, p. 27; Tinning, 2010, p. 28). This supports the call for change in PE-teacher education (e.g., Mordal-Moen \& Green, 2014) in line with etymological and theoretical perspectives from the philosophy of education (e.g., Standal \& Aggerholm, 2016).

\section{Strengths, limitations, and future directions}

Findings related to Interest-based PE should be considered in the light of this study's strengths and weaknesses. Interest-based PE was conducted over a period of two school years involving 348 participants and 345 controls. Its number of participants, duration and longitudinal design lend significant strength to the current study. On the other hand, Interest-based PE being a local initiative performed as a systematic differentiation project, could be considered both a strength and a limitation. The limitation concerns the fact that teachers did not follow a protocol as they taught Interest-based PE. As such, although teachers were taught to teach EA and SA, one cannot completely rule out the possibility that they may have altered other aspects of their teaching during this two-year period (for further detail, please refer to the study by Erdvik, Mordal-Moen, \& Säfvenbom [2019b]). That said, Interest-based PE was developed and performed by PE-teachers within the everyday life of education. This alerts us to the strengths of the current study: Interest-based PE was delivered by the same teachers who hold the key to promote change in PE, thus supporting this study's ecological validity (Schmuckler, 2001). It should also be noted that students with lower levels of autonomy, competence, and relatedness need satisfaction at baseline were more likely to have missing data at later measurement points. Data could therefore not be considered missing at random (Enders, 2010), which could represent a limitation of the current study. With findings suggesting that the promotion of students' basic need satisfaction in PE may require more than "Interest-based PE", we call for more research to increase the understanding of students' experiences with this program. Findings from this study and the study by Erdvik, Mordal-Moen og Säfvenbom (2019b) suggest that future research may do well to combine qualitative and quantitative research designs to deepen our understanding of students' experiences from programmes such as Interest-based PE.

\section{Conclusion}

This study shows that, when given the opportunity, girls, non-sports-active students, and students who experience low basic need satisfaction in PE tend to deselect a sports approach to PE. This highlights the need for short and long-term changes in PE to level the playing field for these students and ensure that PE is a subject for all. Yet, participation in Interest-based PE and a choice of two PE approaches did not appear to promote students' basic need satisfaction, and non-sports-active students 


\section{B. Erdvik et al.}

did not appear to experience more basic need benefits through Interest-based PE than sports active students. This suggests that PE remains a context that favours sports-active adolescents, regardless of Interest-based PE, and that the challenges in promoting basic need satisfaction in PE may require more than "Interest-based PE". While students' basic need satisfaction in PE may be promoted through the use of more specific need supportive strategies, this study highlights the need for long-term strategies targeting PE discourses, teacher habitus, and curriculum interpretation in order to reduce student inequity in PE.

\section{Author biography}

Irina Burchard Erdvik is employed at the Faculty for Social and Health Sciences at the Inland Norway University of Applied Sciences, and is a $\mathrm{PhD}$ candidate at the Department of Physical Education at the Norwegian School of Sport Sciences. Her doctoral dissertation focuses on experiences in physical education in relation to adolescent development.

Tommy Haugen is associate professor at the Faculty of Health and Sports Sciences at the University of Agder. His research interests include group dynamics and psychological aspects in sports and physical education.

Andreas Ivarsson, PhD, works at the Center of Research on Welfare, Health and Sport at Halmstad University. His research interest includes psychological aspects related to sport injuries, motivational aspects related to sport and exercise participation, statistical and methodological issues within psychological research, and mindfulness.

Reidar Säfvenbom is associate professor at the Department of Physical Education at the Norwegian School of Sport Sciences. His research interests are in the relevance of physical activity contexts in the everyday life of adolescents.

\section{References}

Akkerman, A., Kef, S., \& Meininger, H. P. (2017). Job satisfaction of people with intellectual disabilities: The role of basic psychological need fulfillment and workplace participation. Disability and Rehabilitation, 40(10), 1-8. doi:10.1080/09638288.2017.1294205.

Bagøien, T. E., Halvari, H., \& Nesheim, H. (2010). Self-determined motivation in physical education and its links to motivation for leisure-time physical activity, physical activity, and well-being in general. Perceptual and Motor Skills, 111(2), 407-432. doi:10.2466/06.10.11.13.14.PMS.111.5.407-432.

Chen, W. (2014). Psychological needs satisfaction, motivational regulations and physical activity intention among elementary school students. Educational Psychology, 34(4), 495-511. doi:10.1080/01443410.201 3.822959 .

Cohen, J. (1988). Statistical power analysis for the behavioural sciences (2nd ed.). Hillsdale, NJ: Lawrence Erlbaum Associates.

Cothran, D. J. (2010). Students' curricular values and expereinces. In M. O’Sullivan \& A. MacPhail (Eds.), Young people's voices in physical education and youth sport (pp. 49-62). New York: Routledge.

Deci, E. L., \& Ryan, R. M. (2000). The "what" and "why" of goal pursuits: Human needs and the selfdetermination of behavior. Psychological Inquiry, 11(4), 227-268. doi:10.1207/S15327965PLI1104_01.

Enders, C. K. (2010). Applied missing data analysis. New York: Guilford Publications. 


\section{Development of basic psychological need satisfaction in physical education}

Erdvik, I. B., Øverby, N. C., \& Haugen, T. (2014). Students' self-determined motivation in physical education and intention to be physically active after graduation: The role of perceived competence and identity. Fournal of Physical Education and Sport, 14(2), 232-241. doi:10.7752/jpes.2014.02035.

Erdvik, I. B., Haugen, T., Ivarsson, A., \& Säfvenbom, R. (2019a). Global self-worth among adolescents: The role of basic psychological need satisfaction in physical education. Scandinavian fournal of Educational Research. Advance online publication. doi:10.1080/00313831.2019.1600578.

Erdvik, I. B., Mordal-Moen, K., \& Säfvenbom, R. (2019b). Students' experiences from a physical education intervention: Choosing between an explorative model and a sport model of PE. Manuscript in preparation.

Erturan-İlker, G., Quested, E., Appleton, P., \& Duda, J. L. (2018). A cross-cultural study testing the universality of basic psychological needs theory across different academic subjects. Psychology in the Schools, 55(4), 350-365. doi:10.1002/pits.22113.

Gagne, M., Ryan, R. M., \& Bargmann, K. (2003). Autonomy support and need satisfaction in the motivation and well-being of gymnasts. Fournal of Applied Sport Psychology, 15(4), 372-390. doi:10.1080/714044203.

Garn, A. C., McCaughtry, N., Martin, J., Shen, B., \& Fahlman, M. (2012). A basic needs theory investigation of adolescents' physical self-concept and global self-esteem. International fournal of Sport and Exercise Psychology, 10(4), 314-328. doi:10.1080/1612197X.2012.705521.

Green, K. (2000). Exploring the everyday "philosophies" of physical education teachers from a sociological perspective. Sport, Education and Society, 5(2), 109-129. doi:10.1080/713696029.

Hay, P. J., \& Macdonald, D. (2010). Evidence for the social construction of ability in physical education. Sport, Education and Society, 15(1), 1-18. doi:10.1080/13573320903217075.

How, Y. M., Whipp, P. R., Dimmock, J. A., \& Jackson, B. (2013). The effects of choice on autonomous motivation, perceived autonomy support, and physical activity levels in high school physical education. Fournal of Teaching in Physical Education, 32(2), 131-148. doi:10.1123/jtpe.32.2.131.

Katz, I., \& Assor, A. (2007). When choice motivates and when it does not. Educational Psychology Review, 19, 429-442. doi:10.1007/s10648-006-9027-y.

Katz, I., Kaplan, A., \& Buzukashvily, T. (2011). The role of parents' motivation in students' autonomous motivation for doing homework. Learning and Individual Differences, 21(4), 376-386. doi:10.1016/j. lindif.2011.04.001.

Kirk, D. (2010). Physical education futures. New York: Routledge.

Kjønniksen, L., Anderssen, N., \& Wold, B. (2009). Organized youth sport as a predictor of physical activity in adulthood. Scandinavian fournal of Medicine $\mathcal{G}$ Science in Sports, 19(5), 646-654. doi:10.1111/j.16000838.2008.00850.x.

Koka, A., \& Hein, V. (2003). The impact of sports participation after school on intrinsic motivation and perceived learning environment in secondary school physical education. Kinesiology, 35(1), 86-93.

Krijgsman, C., Vansteenkiste, M., van Tartwijk, J., Maes, J., Borghouts, L., Cardon, G., ... Haerens, L. (2017). Performance grading and motivational functioning and fear in physical education: A self-determination theory perspective. Learning and Individual Differences, 55, 202-211. doi:10.1016/j.lindif.2017.03.017.

Leirhaug, P. E., \& Annerstedt, C. (2016). Assessing with new eyes? Assessment for learning in Norwegian physical education. Physical Education and Sport Pedagogy, 21(6), 616-631. doi:10.1080/17408989.2015. 1095871.

López-Pastor, V. M., Kirk, D., Lorente-Catalán, E., MacPhail, A., \& Macdonald, D. (2013). Alternative assessment in physical education: A review of international literature. Sport, Education and Society, 18(1), 57-76. doi:10.1080/13573322.2012.713860.

Marsh, H. W. (2007). Application of confirmatory factor analysis and structural equation modeling in sport and exercise psychology. In G. Tenenbaum, \& R. C. Eklund (Eds.), Handbook of sport psychology (3rd ed., pp. 774-798). Hoboken, NJ: Wiley.

Mordal-Moen, K., \& Green, K. (2014). Neither shaking nor stirring: A case study of reflexivity in Norwegian physical education teacher education. Sport, Education and Society, 19(4), 415-434. doi:10.1080/1357332 2.2012.670114.

Newsom, J. T. (2015). Second-Order Growth Curve Example Syntax: Mplus. Retrieved from http://web.pdx. edu/ newsomj/semclass/ho_growth $2 \% 20$ examples.pdf

Ntoumanis, N. (2001). A self-determination approach to the understanding of motivation in physical education. British fournal of Educational Psychology, 71(2), 225-242. doi:10.1348/000709901158497.

Ntoumanis, N. (2005). A prospective study of participation in optional school physical education using a selfdetermination theory framework. Fournal of Educational Psychology, 97(3), 444-453. doi:10.1037/00220663.97.3.444. 


\section{B. Erdvik et al.}

Ntoumanis, N., Barkoukis, V., \& Thøgersen-Ntoumani, C. (2009). Developmental trajectories of motivation in physical education: Course, demographic differences, and antecedents. Fournal of Educational Psychology, 101(3), 717-728. doi:10.1037/a0014696.

Nyberg, G., \& Larsson, H. (2014). Exploring 'what' to learn in physical education. Physical Education and Sport Pedagogy, 19(2), 123-135. doi:10.1080/17408989.2012.726982.

Opplæringslova [the Norwegian Education Act]. (1998). Lov om grunnskolen og den vidaregåande opplaringa [Act relating to Primary and Secondary Education]. (LOV-1998-07-17-61). Retrieved from https://lovdata.no/ dokument/NL/lov/1998-07-17-61.

Patall, E. A. (2012). The motivational complexity of choosing: A review of theory and research. In R. M. Ryan (Ed.), The Oxford handbook of human motivation (pp. 249-279). Oxford: Oxford University Press.

Redelius, K., \& Hay, P. J. (2012). Student views on criterion-referenced assessment and grading in Swedish physical education. Physical Education E Sport Pedagogy, 17(2), 211-225. doi:10.1080/17408989.2010.5 48064.

Ryan, R. M., \& Deci, E. L. (2017). Self-determination theory: Basic psychological needs in motivation, development, and wellness. New York: Guilford Press.

Ryan, R. M., \& La Guardia, J. G. (2000). What is being optimized?: Self-determination theory and basic psychological needs. In S. H. Qualls \& N. Abeles (Eds.), Psychology and the aging revolution: How we adapt to longer life (pp. 145-172). Washington DC: American Psychological Association.

Säfvenbom, R., Haugen, T., \& Bulie, M. (2015). Attitudes toward and motivation for PE. Who collects the benefits of the subject? Physical Education and Sport Pedagogy, 20(6), 629-646. doi:10.1080/17408989.20 14.892063.

Schmuckler, M. A. (2001). What is ecological validity? A dimensional analysis. Infancy, 2(4), $419-436$. doi:10.1207/S15327078IN0204_02.

Slingerland, M., Borghouts, L., Jans, L., Weeldenburg, G., van Dokkum, G., Vos, S., \& Haerens, L. (2016). Development and optimisation of an in-service teacher training programme on motivational assessment in physical education. European Physical Education Review, 23(1), 91-109. doi:10.1177/1356336X16639212.

Standage, M., Duda, J. L., \& Ntoumanis, N. (2003). A model of contextual motivation in physical education: Using constructs from self-determination and achievement goal theories to predict physical activity intentions. Fournal of Educational Psychology, 95(1), 97-110. doi:10.1037/0022-0663.95.1.97.

Standage, M., Duda, J. L., \& Ntoumanis, N. (2005). A test of self-determination theory in school physical education. British fournal of Educational Psychology, 75(3), 411-433. doi:10.1348/000709904X22359.

Standage, M., Duda, J. L., \& Ntoumanis, N. (2006). Students' motivational processes and their relationship to teacher ratings in school physical education: A self-determination theory approach. Research Quarterly for Exercise and Sport, 77(1), 100-110. doi:10.1080/02701367.2006.10599336.

Standal, Ø. F., \& Aggerholm, K. (2016). Habits, skills and embodied experiences: A contribution to philosophy of physical education. Sport, Ethics and Philosophy, 10(3), 269-282. doi:10.1080/17511321.2016.1220972.

Stolz, S. A. (2014). The philosophy of physical education: A new perspective. London: Routledge.

Stormoen, S., Urke, H. B., Tjomsland, H. E., Wold, B., \& Diseth, A. (2016). High school physical education:What contributes to the experience of flow? European Physical Education Review, 22(3), 355-371. doi:10.1177/ $1356336 \mathrm{X} 15612023$.

Svennberg, L., Meckbach, J., \& Redelius, K. (2018). Swedish PE teachers struggle with assessment in a criterion-referenced grading system. Sport, Education and Society, 23(4), 381-393. doi:10.1080/13573322 .2016 .1200025 .

Tangen, S., \& Husebye, B. N. (2018). Interessebasert kroppsøving [Interest-based physical education]. Manuscript submitted for publication.

Taylor, I. M., \& Lonsdale, C. (2010). Cultural differences in the relationships among autonomy support, psychological need satisfaction, subjective vitality, and effort in British and Chinese physical education. Fournal of Sport E Exercise Psychology, 32(5), 655-673. doi:10.1123/jsep.32.5.655.

Tinning, R. (2010). Pedagogy and human movement: Theory, practice, research. New York: Routledge.

Utdanningsdirektoratet [Norwegian Directorate for Education and Training]. (2015). Lcereplan i kroppsøving [Curriculum for physical education] (KRO1-04). Retrieved from https://www.udir.no/k106/KRO104 ?lplang=eng.

Viira, R., \& Koka, A. (2010). Gender effect on perceived need support from the teacher and peers in physical education. Acta Kinesiologiae Universitatis Tartuensis, 15, 101-108. doi:10.12697/akut.2010.15.06.

Viira, R., \& Koka, A. (2012). Participation in afterschool sport: Relationship to perceived need support, need satisfaction, and motivation in physical education. Kinesiology, 44(2), 199-208. 
Vlachopoulos, S. P., \& Michailidou, S. (2006). Development and initial validation of a measure of autonomy, competence, and relatedness in exercise: The basic psychological needs in exercise scale. Measurement in Physical Education and Exercise Science, 10(3), 179-201. doi:10.1207/s15327841mpee1003_4.

Wright, D. B., London, K., \& Field, A. P. (2011). Using bootstrap estimation and the plug-in principle for clinical psychology data. Fournal of Experimental Psychopathology, 2(2), 252-270. doi:10.5127/jep.013611. 